\title{
Multifield Coupled Dynamic Simulation of Coal Oxidation and Self-Heating in Longwall Coal Mine Gob
}

\author{
Shuanglin Song $\mathbb{D}^{1,2}$ Shugang Wang, ${ }^{1}$ Shuang Jiang, ${ }^{3}$ Yuntao Liang, ${ }^{2}$ and Peiyu Hu ${ }^{1}$ \\ ${ }^{1}$ Faculty of Infrastructure Engineering, Dalian University of Technology, Dalian 116024, Liaoning, China \\ ${ }^{2}$ State Key Laboratory of Coal Mine Safety Technology, CCTEG Shenyang Research Institute, Fushun 113122, Liaoning, China \\ ${ }^{3}$ College of Civil Engineering, Dalian Minzu University, Dalian 116600, Liaoning, China
}

Correspondence should be addressed to Shuanglin Song; songshuangling@163.com

Received 17 February 2020; Revised 3 May 2020; Accepted 19 June 2020; Published 22 July 2020

Academic Editor: Vasilis Burganos

Copyright (c) 2020 Shuanglin Song et al. This is an open access article distributed under the Creative Commons Attribution License, which permits unrestricted use, distribution, and reproduction in any medium, provided the original work is properly cited.

\begin{abstract}
The spontaneous combustion of residual coal in coal mine gob has long been a problem and poses a threat to the safe production of coal. Therefore, it is of great significance to conduct an in-depth study of the oxidation and self-heating progress of residual coal in the gob. Considering that the geometric dimensions and physical characteristics of the gob will change during the advance of the working face, the purpose of the present paper is to determine how the coal self-heating develops during and after coal mining. A fully coupled transient model including gas flow, gas species transport, and heat transfer in the gob and the butt entries, as well as heat transfer in the surrounding strata, is developed to quantify the evolution of coal self-heating in gob during and after mining. The model was solved by COMSOL Multiphysics package and then verified by comparing the field data with the simulated data. On this basis, parametric studies including the influences of the surrounding strata temperature, airflow temperature, coal-rock particle size, and advance rate of the working face on coal oxidation and self-heating in the gob were conducted. The results show that a tailing phenomenon of the high-temperature area is formed on the air inlet side of the gob during mining, and the temperature in the high-temperature zone decreases gradually due to the accumulation and compaction of the gob and heat dissipation to the surrounding strata. Also, although the temperature in gob increases gradually after the stopping of mining, the high-temperature area migrates towards the working face. Moreover, when the temperature of the surrounding strata is consistent, different ventilation temperatures have no obvious effect on the maximum temperature of the gob at the initial mining stage, whereas the higher ventilation temperature results in the higher self-heating temperature after several days of mining. Finally, the smaller average particle size or faster advance rate results in a lower maximum temperature of gob.
\end{abstract}

\section{Introduction}

Spontaneous combustion of residual coal in gob is the most common type of fire in coal mines, accounting for $60 \%$ of underground fire accidents in China [1]. Spontaneous combustion of coal is a phenomenon that commonly occurs in coal mines, which results from the self-ignition of coal following its self-heating in a mine heading or its immediate surrounding [2]. Crushed coal left in the gob and air flowing through the gob with a certain speed, as well as high concentration of oxygen, are the primary determinants of the beginning of the self-heating process, which can begin the spontaneous combustion of coal $[2,3]$. The spontaneous combustion of residual coal in gob is a dynamic development process, which is the result of the comprehensive action of many factors and has strong complexity, variability, and contingency $[4,5]$. In the process of studying the flow, heat transfer, and mass transfer in gob, scholars analyzed the mechanism of the coal-oxygen combination theoretically and studied the distribution law of the airflow field, temperature field, and concentration field in the gob by using the numerical simulation method.

In the research of mathematical models, Zhang and Wang $[6,7]$ established a mathematical model of gas seepage in a gob based on $2 \mathrm{D}$ porous medium steady flow, and the heat exchange with surrounding rock was ignored. Ding 
et al. [8] established a 2D nonlinear seepage equation for the gob and derived a solution for the nonlinear seepage equation. Zhang et al. [9] established a mathematical model of the unsteady temperature field in the gob based on the theory of convective heat and mass transfer. Jiang and Zhang [10] established a 3D flow field mathematical model based on the classic linear Darcy law. Du and Yang [11] built a 3D mathematical model for the unsteady temperature field in the gob using theories of fluid mechanics, heat transfer, and mass transfer. Li et al. [12-14] established a nonsteady mathematical model of coal spontaneous combustion to disclose the distribution laws of air leakage, oxygen concentration, and temperature in the gob based on the air leakage continuity equation, oxygen concentration field equation, and temperature field equation. At the same time, based on mine pressure observation, Li et al. [12] established the finite element seepage mathematical model of gob permeability coefficient distribution by describing the expansion coefficient of collapsed rock. Xu [15] established an unsteady model of the temperature field in the gob to calculate the relationship between the temperature distribution and the advance rate of the working face. Deng et al. [16] established an oxygen concentration distribution model based on heat transfer and conservation of composition mass. Shan et al. [17] established a mathematical model of seepage in the gob based on dispersion dynamics and seepage theories and conducted a related analysis with the finite element algorithm. Hua [18] established a gas fuzzy seepage mathematical equation of the gob based on the irregularity of the gob and the fuzzy mathematical theory. In recent years, with the development of numerical simulation technology, related scholars have established mathematical models for coal spontaneous combustion in the gob. Tan et al. [19] established a one-dimensional model for spontaneous combustion of coal in the gob under moving coordinates through introducing a moving coordinate system to process variations in physical boundaries, which achieved a steady-state transformation of the temperature field. Xia et al. [20] established a thermo-fluid-solid-chemical coupling model to simulate the deformation of coal in the process of coal oxidation and the relationship between permeability and coal temperature. Liu [21], Zhu et al. [22] and Zhang [5] established a coupling model for spontaneous combustion of coal in the gob, which not only realized the dynamic simulation of coal oxidation and self-heating, but also simplified the calculation process. Taraba and Michalec [23] developed a three-dimensional, single-phase model with a continuously advancing longwall face and studied the effect of the longwall face advancing speed on the oxidation heat production as well as the evolution of the gases in the gob area.

In the research of factors affecting the spontaneous combustion of coal in the gob, Brodny and Tutak [24] determined the impact of ventilation airflow volume on the location of the special hazard zone with endogenous fire in the gob and pointed out that the ventilation rate of the air had a significant impact on the location and the range of the special hazard spontaneous fire zone. Wen [25] thought that coal spontaneous combustion in the gob was mainly determined by the thickness of residual coal, air leakage intensity, oxygen concentration, advance rate of working face, and spontaneous combustion period. Then, the risk of spontaneous combustion of coal in the gob under a different advance rate of working face and air leakage intensity was predicted [26]. In the model established by Ejlali et al. [27] and Lohrer et al. [28], the effect of moisture on the heat transfer process was considered. Yang et al. [29] theoretically analyzed the influence of changes in air volume and pressure on the spontaneous combustion status of coal in the gob and divided the range of the oxidation zone in the gob by numerical simulation under different conditions. Wang et al. [30] established a dynamic model of the porosity in the gob with the variation of position. Li et al. [31] explained the abrupt change of temperature rise and variability of factors of coal spontaneous combustion based on the carving coalrock " $\mathrm{O}$ " ring theory of the gob and the nonuniform distribution characteristics of coal-rock and oxygen consumption. Tutak and Brodny [3] studied the influence of the tensile strength of roof rocks on the extent of the zone with a particularly high risk of spontaneous coal combustion in caving goaves of the longwalls ventilated with the Y-type system. Yuan and Smith [32] studied the effects of coal properties (coal surface area and heat of reaction) on spontaneous heating in longwall gob (mined-out) areas by using FLUENT software.

Since spontaneous combustion of coal in the gob is a multifield coupling process involving airflow, stress, fracture, oxygen concentration, and temperature, some scholars have studied the evolution of coal spontaneous combustion in high-temperature areas with the multifield coupling research method [21, 33-36]. Meanwhile, there are a variety of unsteady factors that can affect the process of spontaneous combustion of coal, such as the air pressure disturbance caused by the variation of the ventilation system, the enlarged physical dimension of the seepage field near working face, and the changes of physical properties of porous skeletons affected by the overlying strata and compaction in the gob, which requires that the physical model established in numerical simulation research be as close to the site conditions as possible. Therefore, the dynamic grid technology [37] of CFD software was employed by some scholars to obtain the heterogeneous distribution of porosity in time and space, and the simulation result was more in line with the actual situation. Besides, some scholars combined COMSOL Multiphysics ${ }^{\circledR}$ with MATLAB to generate a new mine gob grid and took the field information of the last time step as the initial value of the current time step. Thus, the continuity of simulated physical quantity was achieved in time and space, which reflects the heating process of coal spontaneous combustion in gob to a large extent $[4,38,39]$.

However, the above studies did not consider the influence of factors such as the surrounding strata temperature and ventilation temperature on the spontaneous combustion of residual coal in the gob. Besides, the evolution of the hightemperature area in the mined-out gob still needs to be discussed when stopping mining, for which the self-heating process has lasted for several days since the start of the mining activity. 
Considering that the gob environment is always dynamically changed in the mining process, the openings of the butt entries as well as the surrounding strata were taken as the boundary to jointly solve the physical fields of these different areas in this study. In this way, the dynamic evolution of coal oxidation and self-heating in the gob was studied during and after the coal mining, which can not only improve the prediction level of coal spontaneous combustion but also provide a new technical means for delineating the location of hidden fire sources in the gob.

\section{Problem Description}

Longwall mining is an exploitation method used in flatlying, relatively thin tabular coal seams in which a long face is established to extract the coal. The length of longwall working face in China is generally $80 \mathrm{~m}-250 \mathrm{~m}$, and there are $300 \mathrm{~m}$ long working faces in recent years. The simplest roadway system of longwall working face includes open-off cut, the butt entries (including working face, section headentry, and section tailentry), and the gob. The coal mining activity starts from the open-off cut. One side of the open-off cut is the coal wall to be mined, and coal is dropped, loaded, and transported along the coal wall of the working face. With the development of coal mining, gob is gradually formed. With the continuous advance of the working face, the size of the mined-out area continues to expand.

The layout of a typical longwall section with "U type" ventilation system is shown in Figure 1. The working face advances with a rate of $u_{\text {work }}$, resulting in a decreasing area of the entity coal and an increasing area of the gob. The airflow rate in the entries can be controlled by using bleeders and regulators so that the methane accumulation is kept away from coal mining. Because of the void in the gob, the air flows through the gob with a certain speed and carries high concentration of oxygen into the gob as well, resulting in the coal oxidation process, which generates heat in this reaction. The heat can be continuously produced if air supply is not eliminated. The generated heat is transported out of the gob by conduction through coal mass, convection through flow, and radiation. If the rate of heat generation is greater than that dissipated to the external environment, the excessive heat will result in temperature rise in the gob.

Under the dual effects of gravity and mining stress, the overlying strata continue to fall into the mined-out area, forming a porous medium filling space with certain distribution laws. According to the distribution of mining stress, the gob can be divided into three parts: coal pillar supporting influence zone, the stress transition area, and the recompaction area [40]. Different areas show different stacking patterns, with significant heterogeneity. In the area close to the working face and butt entries, because of the support of coal pillar, the gob is not pressed by the cantilever beam and overlying rock. The collapsed coal and rock mass are in the state of free accumulation. With good permeability and large air leakage flow, the basic conditions of coal spontaneous combustion are easy to meet. Therefore, these areas are also high-risk areas of coal oxidation and even spontaneous combustion. Because of the large mining intensity of the longwall mining method, the gob formed in the underground is also large, and the residual coal in the gob is easy to ignite naturally.

\section{Multifield Coupled Dynamic Model}

\subsection{Assumptions}

(1) The length of the strike and dip of the gob is much larger than the carving height of the overlying strata caused by coal seam mining, so the variations of the physical parameters in the height of the gob are ignored; i.e., a 2D model is assumed and implemented

(2) Physical parameters of the air and coal gangue are not varied with temperature

(3) The effect of water vapor in the process of coal oxidation and self-heating is ignored

3.2. Dynamic Evolution of Porosity and Permeability in the Gob. The dynamic evolution of the longwall section during the mining process is shown in Figure 1. With the advance of the working face, rock and residual coal in the free carving zone are gradually compacted under the effect of gravity and mining stress. The bulking factor is continuously decreased in the compaction process, and its value can be expressed by [31]

$$
\left\{\begin{aligned}
K_{p}(x, y)= & K_{p, \min }+\left(K_{p, \max }-K_{p, \min }\right) \exp \\
& \left\{-a_{x} d_{x}\left[1-\exp \left(-\xi a_{y} d_{y}\right)\right]\right\}, \\
\xi_{1}<1, &
\end{aligned}\right.
$$

where $K_{p}(x, y)$ is the bulking factor (distribution function) of the gob, dimensionless; $K_{p}$, max is the initial caving and crushing expansion coefficient, dimensionless; $K_{p}$, min is the crushing expansion coefficient after caving compaction, dimensionless; $\alpha_{y}$ and $\alpha_{x}$ are the attenuation rates at the strike and dip direction of the crushing expansion coefficient in the gob, respectively $\left(\mathrm{m}^{-1}\right)$, which are related to the physical and mechanical properties of the caving coal and rock, the geological characteristics of strata, the load of mining stress, and the caving duration (the advance of the working face); $d_{y}$ and $d_{x}$ are the distances from any point ( $x$, $y$ ) in the gob to a fixed surrounding solid boundary and the working face boundary, respectively $(\mathrm{m}) ; \xi$ is the adjustment coefficient for controlling the distribution morphology of the "O" ring model (the larger the $\xi$ is, the more likely the quadrate will be presented).

If the advance rate of the working face is $u_{\text {work }}$, the distance from any point in the gob $(x, y)$ to a fixed surrounding solid boundary of the gob and the working face over time can be expressed as

$$
\left\{\begin{array}{l}
d_{x}=x-x_{0}+u_{\text {work }} t \\
d_{y}=0.5 L-|y-0.5 L| .
\end{array}\right.
$$

The height of the caving zone and the porosity can be expressed as [41] 


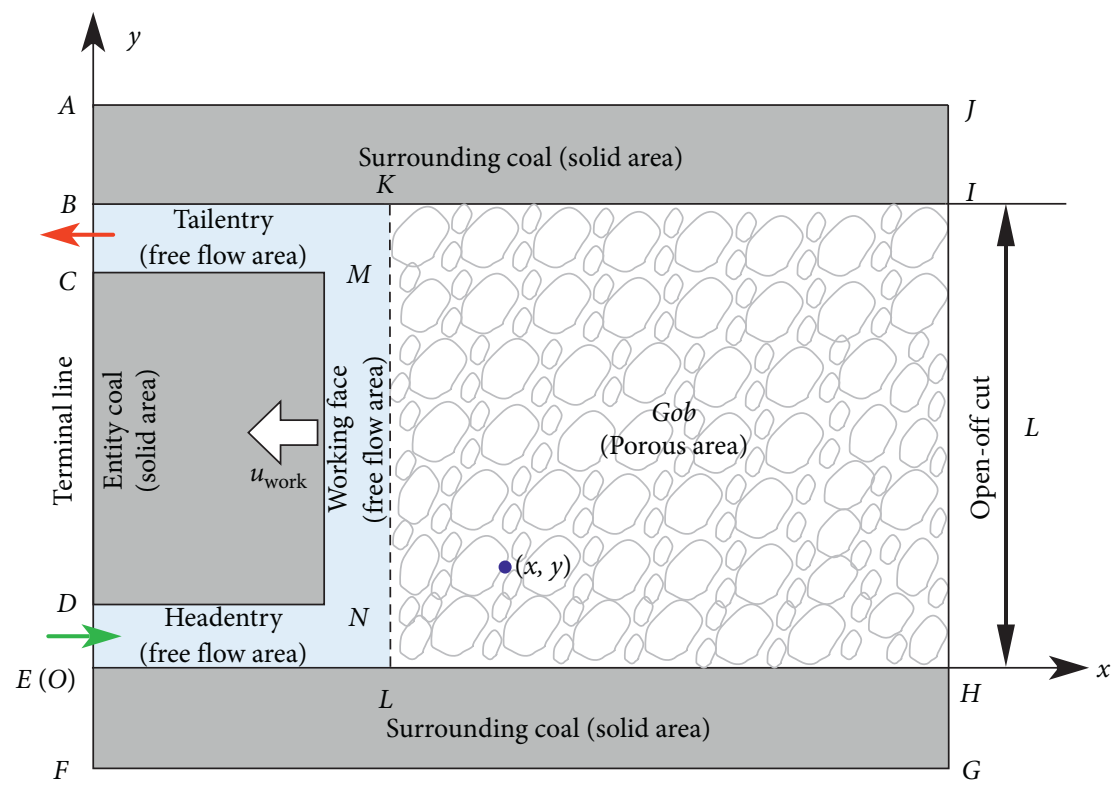

FIGURE 1: 2D schematic diagram of longwall section with "U type" ventilation system.

$$
\begin{aligned}
& H=\frac{M K_{p}(x, y)}{K_{p, \text { max }}-1}, \\
& \varepsilon=1-\frac{1}{K_{p}(x, y)},
\end{aligned}
$$

where $H$ is the caving height (m); $\varepsilon$ is the porosity; and $M$ is the mining height of the working face $(\mathrm{m})$.

According to Ergun's experimental research [42], the gob permeability can be calculated by the porosity and volume average particle size:

$$
k=\frac{\varepsilon^{3} d_{p}^{2}}{150(1-\varepsilon)^{2}},
$$

where $k$ is the permeability of the gob $\left(\mathrm{m}^{2}\right)$; and $d_{p}$ is the particle diameter of the porous medium of the gob $(\mathrm{m})$.

\subsection{Control Equation of Coal Oxidation and Self-Heating in} the Gob. Assuming that the gas in the gob is incompressible, the continuity equation of gases and fluids can be written as

$$
\rho \nabla \cdot \mathbf{u}=Q_{m}
$$

where $\mathbf{u}$ is the Darcy velocity field in the gob $\left(\mathrm{m} \cdot \mathrm{s}^{-1}\right)$; and $Q_{m}$ is the source (sink) term of the gas $\left(\mathrm{kg} \cdot \mathrm{m}^{-3} \cdot \mathrm{s}^{-1}\right)$.

The permeability in the gob has obvious heterogeneous characteristics. The airflow is in a turbulent state when its velocity is large in the gob near the working face, while the airflow is in a laminar or peristaltic state when its velocity is low inside the gob. Therefore, the Darcy-Brinkman equation was used to describe the airflow in the gob [43].

$$
\frac{\rho}{\varepsilon}(\mathbf{u} \cdot \nabla) \frac{\mathbf{u}}{\varepsilon}=\nabla \cdot[-p \mathbf{I}+\mathrm{K}]-\left(\mu k^{-1}+\beta \varepsilon \rho|\mathbf{u}|+\frac{Q_{m}}{\varepsilon^{2}}\right) \mathbf{u},
$$

where $\mathbf{K}=(\mu / \varepsilon)\left\{\left(\nabla \mathbf{u}+(\nabla \mathbf{u})^{\mathrm{T}}\right)-(2 / 3)(\nabla \cdot \mathbf{u}) \mathbf{I}\right\} ; p$ is the gas pressure in the gob $(\mathrm{Pa}) ; \mu$ is the dynamic viscosity of the mixed gas in the gob $(\mathrm{Pa} \cdot \mathrm{s}) ;|\mathbf{u}|$ is the magnitude of the velocity $\left(\mathrm{m} \cdot \mathrm{s}^{-1}\right)$, for the $2 \mathrm{D}$ model $|\mathbf{u}|=\sqrt{u^{2}+v^{2}} ; \rho_{g}$ is the density of the mixed gas in the gob $\left(\mathrm{kg} \cdot \mathrm{m}^{-3}\right) ; \beta$ is defined as

$$
\beta=\frac{c_{F}}{\sqrt{k}},
$$

where $c_{F}$ is the gas drag coefficient and defined as

$$
c_{F}=\frac{1.75}{\sqrt{150 \varepsilon^{3}}} \text {. }
$$

The gas concentration equation in the gob can be expressed as [44]

$$
\varepsilon \frac{\partial C_{i}}{\partial t}+(\mathbf{u} \cdot \nabla) C_{i}=\nabla \cdot\left(\varepsilon D_{e, i} \nabla C_{i}\right)+\varepsilon r_{i},
$$

where $C_{i}$ is the substance concentration $\left(\mathrm{mol} \cdot \mathrm{m}^{-3}\right) ; D_{e_{i} i}$ is the effective diffusion coefficient $\left(\mathrm{m}^{2} \cdot \mathrm{s}^{-1}\right)$, defined as $\varepsilon^{4 / 3} D_{i}$; and $r_{i}$ is the reaction rate expression for the species $\left(\mathrm{mol} \cdot \mathrm{m}^{-3} \cdot \mathrm{s}^{-1}\right)$. The oxygen concentration is the most important component among a variety of gas species in the gob, which determines the rate of coal oxidation reaction. The chemical reaction between coal and oxygen can be simplified as [32]

$$
\mathrm{Coal}+\mathrm{O}_{2} \longrightarrow \mathrm{CO}_{2}+0.1 \mathrm{CO}+\text { heat }
$$

In this paper, only oxygen $\left(\mathrm{O}_{2}\right)$ and carbon monoxide (CO) are calculated in the model. The reaction rate of $\mathrm{CO}$ can be determined from the stoichiometric relationship between $\mathrm{O}_{2}$ and $\mathrm{CO}$ in reaction (10), and the $\mathrm{O}_{2}$ consumption rate is related to the oxygen concentration and coal oxidation parameters, which can be expressed by the Arrhenius equation: 


$$
r_{\left(\mathrm{O}_{2}\right)}=-\frac{H_{1}}{H}\left(C_{\left(\mathrm{O}_{2}\right)}\right)^{n} A e^{-(E / \mathrm{RT})},
$$

where $r_{\left(\mathrm{O}_{2}\right)}$ is the consumption rate of $\mathrm{O}_{2}\left(\mathrm{~mol} \cdot \mathrm{m}^{-3} \cdot \mathrm{s}^{-1}\right)$; $\mathrm{C}_{\left(\mathrm{O}_{2}\right)}$ is the oxygen concentration $\left(\mathrm{mol} \cdot \mathrm{m}^{-3}\right) ; A$ is the preexponential factor $\left(\mathrm{s}^{-1}\right) ; E$ is the activation energy $\left(\mathrm{J} \cdot \mathrm{mol}^{-1}\right)$; $R$ is the gas constant $\left(\mathrm{J} \cdot \mathrm{mol}^{-1} \cdot \mathrm{K}^{-1}\right) ; n$ is the reaction order, which is unity in this study; and $H_{1}$ is the thickness of the residual coal in gob $(\mathrm{m})$.

Based on the conservation of energy, energy equations of air and coal-rock can be written as

$$
\begin{gathered}
\varepsilon\left(\rho c_{p}\right)_{f} \frac{\partial T_{f}}{\partial t}+\left(\rho c_{p}\right)_{f} \mathbf{u} \cdot \nabla T_{f}=\nabla \cdot\left(\varepsilon \lambda_{f} \nabla T_{f}\right) \\
+\frac{6(1-\varepsilon) h_{s f}}{d_{p}}\left(T_{s}-T_{f}\right), \\
(1-\varepsilon)(\rho c)_{s} \frac{\partial T_{s}}{\partial t}=\nabla \cdot\left[(1-\varepsilon) \lambda_{s} \nabla T_{s}\right] \\
+(1-\varepsilon)\left(q_{s}-q_{0, u}\right)+\nabla \mathbf{F}-\frac{6(1-\varepsilon) h_{s f}}{d_{p}}\left(T_{s}-T_{f}\right),
\end{gathered}
$$

where the subscripts $s$ and $f$ represent solid and fluid, respectively; $T$ is the temperature $(\mathrm{K}) ; c$ and $c_{p}$ are solid specific heat and fluid constant pressure specific heat, respectively $\left(\mathrm{J} \cdot \mathrm{kg}^{-1} \cdot \mathrm{K}^{-1}\right)$; $t$ is time $(\mathrm{s}) ; h$ is convective heat transfer coefficient $\left(\mathrm{W} \cdot \mathrm{m}^{2} \cdot \mathrm{K}^{-1}\right) ; \lambda$ is the thermal conductivity $\left(\mathrm{W} \cdot \mathrm{m}^{-1} \cdot \mathrm{K}^{-1}\right) ; \mathrm{F}$ is the radiant flux vector $\left(\mathrm{W} \cdot \mathrm{m}^{-2}\right) ; q_{s}$ is the solid heat generation term $\left(\mathrm{W} \cdot \mathrm{m}^{-3}\right)$. As it is related to the coal-oxygen reaction process, $q_{s}$ can be calculated with [45]

$$
q_{s}=-r\left(\mathrm{O}_{2}\right) \Delta H
$$

where $\Delta H$ is the amount of thermal generation during the oxidation reaction of coal $\left(\mathrm{J} \cdot \mathrm{mol}^{-1}\right)$, which can be obtained through coal sample experiments.

The radiant flux $\mathbf{F}$ should not be ignored when the local temperature of the coal-rock is high. It can be calculated in various methods. A simple approximation method can be used for the coal-rock; that is, radiative heat transfer is approximately processed into a diffusion process that is similar to heat conduction [45]. It can be calculated as follows:

$$
\mathbf{F}=\beta_{R} T^{3} \nabla T=\lambda_{r} \nabla T,
$$

where $\beta_{R}$ is constant $\left(\mathrm{W} \cdot \mathrm{m}^{-1} \cdot \mathrm{K}^{-4}\right)$; and $\lambda_{r}$ is the radiation thermal conductivity $\left(\mathrm{W} \cdot \mathrm{m}^{-1} \cdot \mathrm{K}^{-1}\right)$.

Considering that enough heat exchange can be conducted between air and coal-rock with the low seepage velocity in the coal-rock, the fluid temperature is consistent with the temperature of the coal-rock mass ( or $T_{f}=T_{s}=T$ ). By adding (12) and (13), the heat transfer equation can be expressed as [44]

$$
\begin{aligned}
(\rho c)_{m} \frac{\partial T}{\partial t}+\left(\rho c_{p}\right)_{f} \mathbf{u} \cdot \nabla T= & \nabla \cdot\left(\lambda_{m} \nabla T\right) \\
& +(1-\varepsilon)\left(q_{s}-q_{0}\right)+\nabla \mathbf{F}
\end{aligned}
$$

where the subscript $m$ is the average volume, and $(\rho c)_{m}=\varepsilon\left(\rho c_{p}\right)_{f}+(1-\varepsilon)(\rho c)_{s}, \lambda_{m}=\varepsilon \lambda_{f}+(1-\varepsilon) \lambda_{s}$.

During the advance of the working face, the surface heat flux $q_{0}$ at the boundary of the top and bottom plates can be calculated by [13]

$$
q_{0}=-\sqrt{\frac{u_{\mathrm{work}} \lambda_{s}(\rho c)_{s}}{\pi d_{2}}}\left(T-T_{W}\right) .
$$

3.4. Control Equations of the Butt Entries. Since the airflow in the working face, headentry, and tailentry are generally turbulent in the coal mine, a turbulence model is required for simulation. Two-equation models, algebraic turbulence models, and large eddy simulation models are common turbulence models. The LVEL turbulence model [46] used in this paper is based on Prandtl's mixed length theory, which calculates turbulent viscosity stably and efficiently based on local speed and distance from the nearest wall and is suitable for calculating internal flow. The gas composition and heat transfer equation are shown as follows:

$$
\left\{\begin{array}{l}
\frac{\partial C_{b, i}}{\partial t}+(\mathbf{u} \cdot \nabla) C_{b, i}=\nabla \cdot\left(D_{i} \nabla C_{b, i}\right), \\
\left(\rho c_{p}\right)_{f} \frac{\partial T_{b}}{\partial t}+\rho c_{p} \mathbf{u} \cdot \nabla T_{b}+\nabla \cdot\left(\lambda_{f} \nabla T_{b}\right)=0,
\end{array}\right.
$$

where $C_{b, i}$ is the substance concentration $\left(\mathrm{mol} \cdot \mathrm{m}^{-3}\right) ; D_{i}$ is the gas diffusion coefficient $\left(\mathrm{m}^{2} \cdot \mathrm{s}^{-1}\right)$ in free flow; $T_{b}$ is the air temperature in the butt entries $(\mathrm{K})$. The gas species of $\mathrm{O}_{2}$ and $\mathrm{CO}$ are considered in equation (18), and no reactions are considered beyond the gob area.

3.5. Solid Heat Transfer Equation for Surrounding Strata. The heat transfer of the surrounding strata is primarily dominated by heat conduction, which can be expressed as

$$
(\rho c) \frac{\partial T_{s}}{\partial t}+\nabla \cdot\left(\lambda_{s} \nabla T_{s}\right)=0 .
$$

3.6. Cross-Coupling Relations and the Simulation Environment. The established model has a coupling relationship in three aspects. First, the gob energy equation and the gas composition equation were coupled mutually inside the gob and were related to the velocity field solved by the gob flow equation. Secondly, the gas heat transfer equation and gas concentration equation of the butt entries were related to the internal velocity field inside them. Finally, the values of temperature, airflow velocity, pressure, and gas concentration at the interface between different computational domains were equal and continuous. The coupling relationship is shown in Figure 2.

The established model consists of several nonlinear partial differential equations in space and time and cannot be analytically solved. Therefore, a multiphysics modeling environment, the COMSOLMultiphysics ${ }^{\circledR}$, is implemented. COMSOLMultiphysics employs the Finite Element Method 


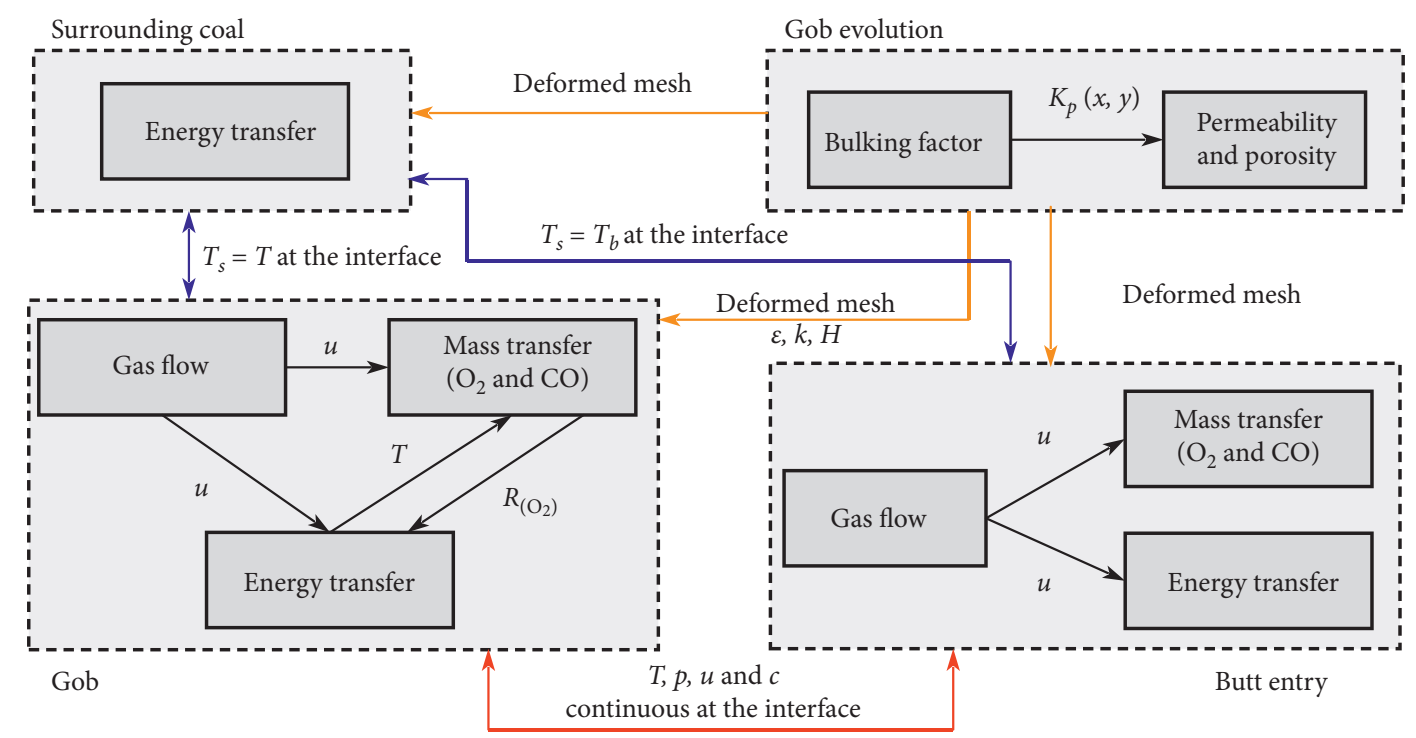

FIGURE 2: Multiphysics coupling relationship of the model.

and is capable of handling PDEs and DAEs. A segregated solution approach was chosen for the simulation, which splits the solution process into substeps.

Besides, with the advance of the working face, the area of the gob will be continuously increased, and the physical size of the calculation area will be constantly varied (as shown in Figure 3 ). Therefore, the calculation grid will be also adjusted accordingly. The deformation geometry model established by COMSOLMultiphysics realized the free deformation of the mesh by setting the moving speed of the calculation boundary, thereby simulating the dynamic growth of the gob.

\section{Model Verification}

To verify the reliability of the multifield coupling model established in this paper, test data acquired from the E12604 working face of Cuijiazhai Coal Mine of Kailuan Group [47] were compared with the calculation results obtained in this paper. The advancing distance of the E12604 working face is $570 \mathrm{~m}$, and the average distance in the dip direction is $135 \mathrm{~m}$. The coal mining method is longwall mining on strike, the coal seam thickness is $3 \mathrm{~m}-3.2 \mathrm{~m}$, and the mining height is $2.8 \mathrm{~m}-3 \mathrm{~m}$. The onsite data monitoring point was located $2.5 \mathrm{~m}$ above the floor of tailentry pillar close to the gob and $120 \mathrm{~m}$ away from the open-off cut of the E12604 working face [48]. According to the actual situation, the boundary and initial conditions of the mathematical model are shown in Tables 1 and 2, and the numerical calculation parameters are shown in Table 3.

Comparison results between the numerical simulation and the measured data are shown in Figure 4. Figures 4(a) and 4(b) show the changes in gas temperature and oxygen concentration at the monitoring points in front of the working face, respectively. It can be seen from Figure 4(a) that the simulation and measured results of the temperature of the gob at the early stage of mining were very close.
However, the simulation temperature at the measured point was gradually higher than the measured temperature with the increase of advance distance. The main reason for the above phenomenon may be that there will be gas inflow from the adjacent gob in the actual mine. The simulation oxygen concentration in Figure 4(b) was consistent with the measured value. The initial oxygen concentration at the working face was high. However, with the increase of the advance distance, as the coal oxidation gradually consumed the oxygen in the gob, the oxygen concentration decreased continuously. It can be generally considered that the dynamic variation of the coal oxidation process in the gob with the advance of the working face could be well described by the model established in this paper.

The simulation result of the variation of porosity in the gob during the advance of the working face is shown in Figure 5. It can be seen from this figure that the distribution of porosity in the gob is not uniform. Overall, the porosity of the area near the working face and the two butt entries is large due to the supporting effect of the hydraulic support and the coal pillars, while the porosity of the area far away from the working face and the double roadway is small, which is mainly due to the good compaction under the action of greater ground stress. Therefore, the distribution of porosity in the gob is characterized by typical O-ring. With the continuous advance of the working face, the scope of the gob area is expanding, and the length of the gob on the strike is increasing. Although the size of the "O" ring increased continuously, the distribution law of porosity in the gob remained unchanged. The minimum porosity in the gob is 0.15 at the initial stage and 0.13 at the later stage, while the porosity near the support of the working face is always maintained at about 0.33 , indicating that the gob is gradually compacted with the advance of the working face.

The simulation result of the variation of the temperature field during the advance of the working face is shown in Figure 6. As can be seen from Figures 6(a)-6(d), there is a 


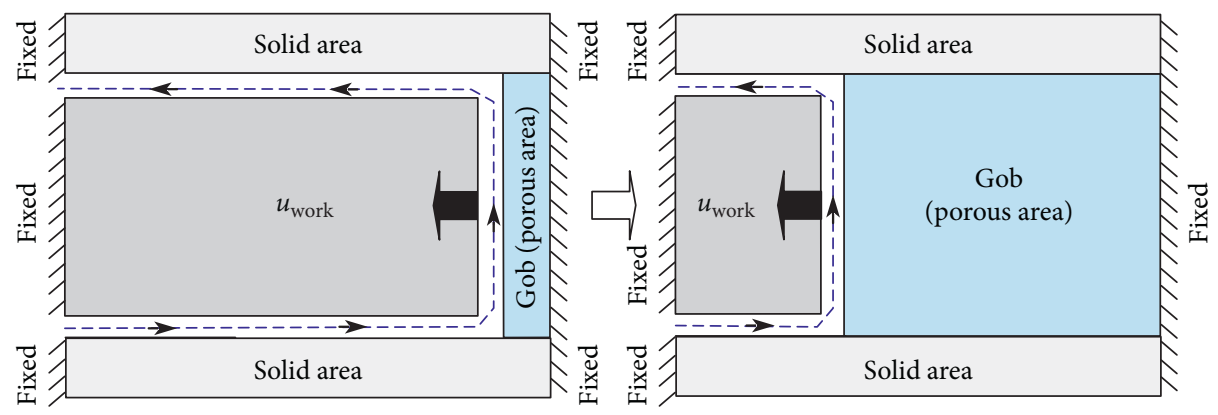

FIgUre 3: Change of computing domain during the dynamic advancement of the gob.

TABLE 1: Boundary conditions.

\begin{tabular}{|c|c|c|c|c|}
\hline Boundary & $\begin{array}{c}\mathrm{AB} / \mathrm{CD} / \mathrm{EF} / \mathrm{FG} / \mathrm{GH} / \mathrm{IJ} / \\
\mathrm{AJ}\end{array}$ & $\mathrm{DE}$ & $\mathrm{BC}$ & $\begin{array}{c}\mathrm{BI} / \mathrm{HI} / \mathrm{EH} / \mathrm{CM} / \\
\mathrm{MN} / \mathrm{DN}\end{array}$ \\
\hline $\begin{array}{l}\text { Boundary } \\
\text { conditions }\end{array}$ & $\mathbf{n} \cdot(\lambda \nabla T)=0$ & $\begin{array}{c}v=v_{\mathrm{in}}, c_{\left(\mathrm{O}_{2}\right)}=c_{0}, c_{(\mathrm{CO})}=0 \\
T=T_{\mathrm{in}}\end{array}$ & $\begin{array}{c}p=0 \text { (outlet), } \mathbf{n} \cdot(\lambda \nabla T)=0 \\
\mathbf{n} \cdot D_{i} \nabla c_{i}=0\end{array}$ & No slip wall \\
\hline
\end{tabular}

TABLE 2: Initial conditions.

\begin{tabular}{cccc}
\hline & Gob & Surrounding strata & Butt entry \\
\hline Initial conditions & $T=T_{W}, C_{\left(\mathrm{O}_{2}\right)}=C_{0}, C_{(\mathrm{CO})}=0$ & $T_{s}=T_{W}$ & $T_{b}=T_{\mathrm{in}}, C_{b,\left(\mathrm{O}_{2}\right)}=C_{0}, C_{b,(\mathrm{CO})}=0$ \\
\hline
\end{tabular}

TABle 3: Numerical simulation parameters.

\begin{tabular}{lcc}
\hline & Parameter & Value \\
\hline Inlet wind velocity & $v_{\text {in }}$ & $1.7 \mathrm{~m} \cdot \mathrm{s}^{-1}$ \\
Reaction order & $n$ & 1 \\
Preexponential factor & $A$ & $0.424 \mathrm{~s}^{-1}$ \\
Activation energy & $E$ & $21.9 \mathrm{~kJ} \cdot \mathrm{mol}^{-1}$ \\
Initial temperature of the surrounding rock & $T_{W}$ & $17^{\circ} \mathrm{C}$ \\
Air density & $\rho_{f}$ & $1.1 \mathrm{~kg} \cdot \mathrm{m}^{-3}$ \\
Heat conduction coefficient of air & $\lambda_{f}$ & $0.026 \mathrm{~W} \cdot \mathrm{m}^{-1} \cdot \mathrm{K}^{-1}$ \\
Specific heat of air & $c_{p}$ & $1012 \mathrm{~J} \cdot \mathrm{kg}^{-1} \cdot \mathrm{K}^{-1}$ \\
Air inlet temperature & $T_{\text {in }}$ & $17^{\circ} \mathrm{C}$ \\
Oxygen concentration in the inlet of airflow & $C_{0}$ & $9.375 \mathrm{~mol} \cdot \mathrm{m}^{-3}$ \\
Heat of oxidation reaction & $\Delta H$ & $400 \mathrm{~kJ} \cdot \mathrm{mol}^{-1}$ \\
Oxygen diffusion coefficient & $D$ & $2 \times 10^{-5} \mathrm{~m} \cdot \mathrm{s}^{-1}$ \\
Density of coal gangue & $\rho_{\mathrm{s}}$ & $1300 \mathrm{~kg} \cdot \mathrm{m}^{-3}$ \\
Heat conduction coefficient of coal gangue & $\lambda_{s}$ & $0.2 \mathrm{~W} \cdot \mathrm{m}^{-1} \cdot \mathrm{K}^{-1}$ \\
Specific heat of coal gangue & $c$ & $1003 \mathrm{~J} \cdot \mathrm{kg}^{-1} \cdot \mathrm{K}^{-1}$ \\
Dynamic viscosity & $\mu$ & $1.84 \times 10^{5} \mathrm{~Pa} \cdot \mathrm{s}$ \\
\hline
\end{tabular}

temperature rise zone within a certain range of the gob during mining. This area first appears near the headentry near the working face. With the advance of the working face, the coverage of the temperature rise zone in the gob gradually expands to the air return side and moves upward and forward. And as the distance in the advancing direction increases, its relative distance from the working face remains unchanged. When the working face advances for a certain distance, the range of the temperature rise zone in the gob moves forward instead of increasing with the advance of the working face, showing a shape of "wing section" on the chart. It can be seen from Figure 6(e) that the high-temperature zone in the gob can still be seen after the mining is stopped and is approaching the terminal line. The terminal line is about $100 \mathrm{~m}$ away from the center of the high-temperature zone with the highest temperature of $64.2^{\circ} \mathrm{C}$.

The simulation result of the variation of the oxygen concentration field in the gob during the advance of the working face is shown in Figure 7. From Figures $7(a)-7(d)$, it can be seen that the oxygen concentration in the gob is asymmetrically distributed. The high oxygen concentration distribution area in the gob on the air inlet side is deeper than that on the return side. The isoline distribution of oxygen concentration and the relative distance between the working face is fixed. It can be seen from Figure 7(e) that the shape of the oxygen distribution area in the gob at 10 days 


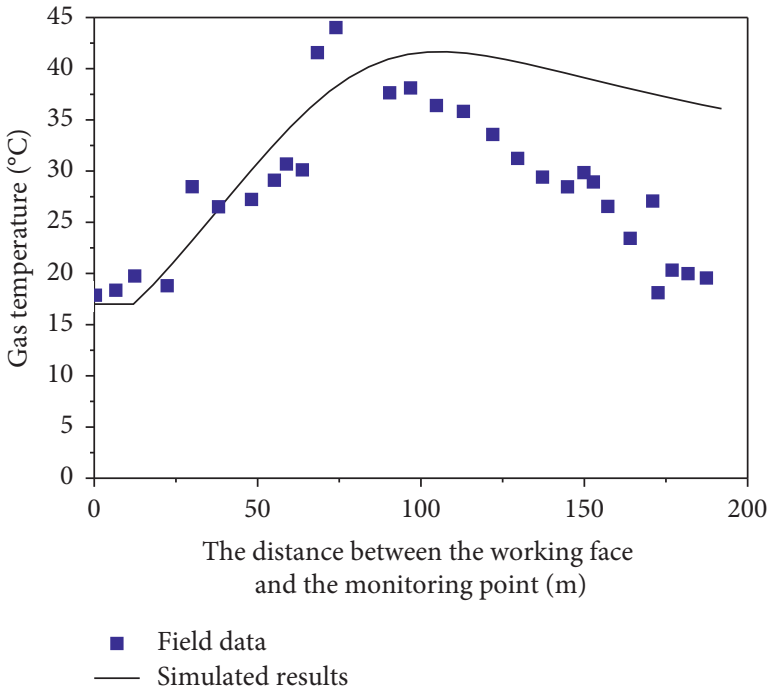

(a)

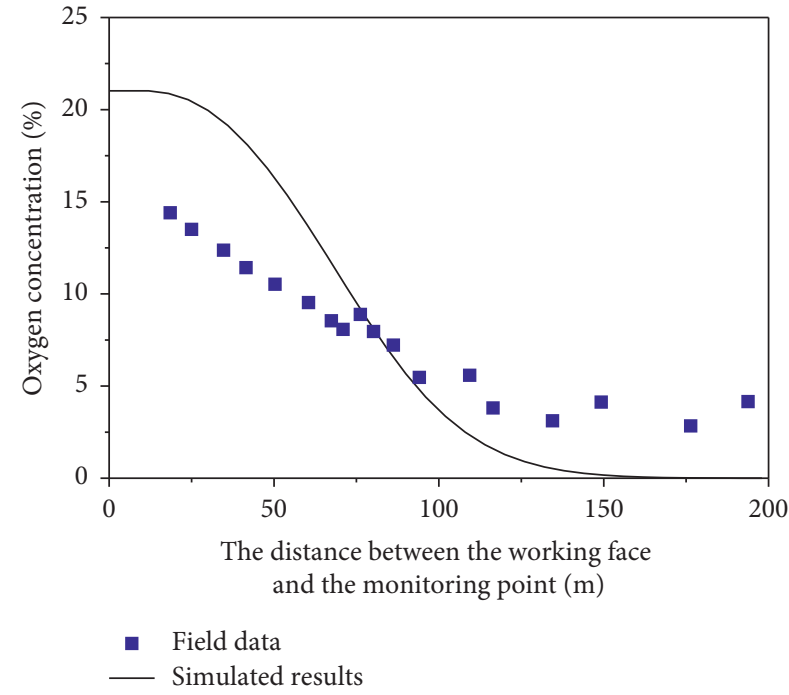

(b)

FIgURE 4: Comparison between the numerical results and the field data.

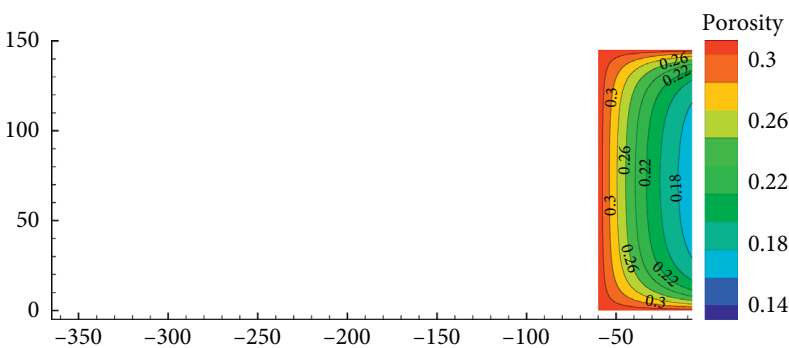

(a)

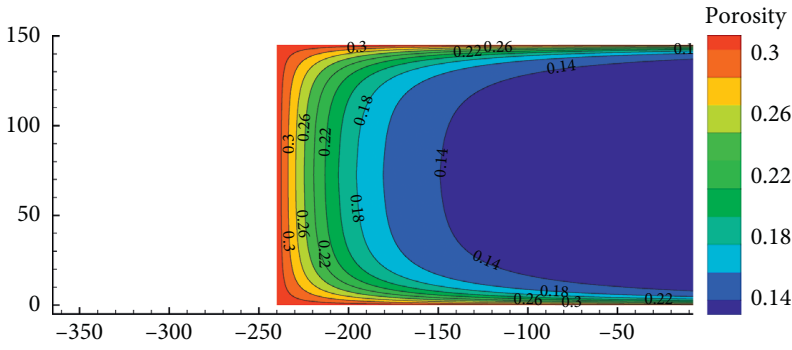

(c)

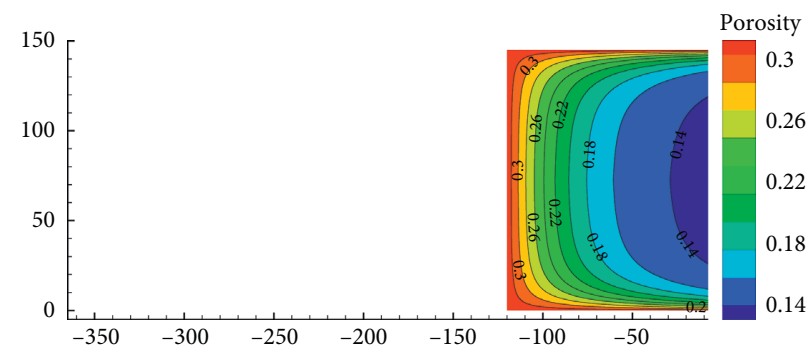

(b)

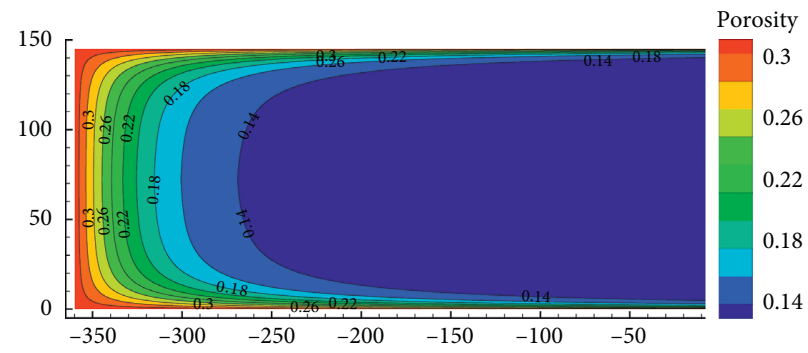

(d)

FIGURE 5: Dynamic variation of porosity in the gob during the advance of the working face. (a) 10 days after the advance of the working face. (b) 20 days after the advance of the working face. (c) 40 days after the advance of the working face. (d) 60 days after the advance of the working face.

after the stopping of mining has little change compared with the normal mining period, which is still asymmetrically distributed and the width at the air inlet side is larger than that of the air return side. However, a decline in the total width is observed. The reason is that the path for transporting oxygen in the gob is cut off after the closure of the working face. As a result, the concentration of oxygen in the gob decreases gradually with the oxidation process.

The simulation result of the variation of the CO concentration field in the gob during the advance of the working face is shown in Figure 8. It can be seen from Figures 8(a)$8(\mathrm{e})$ that the shape of the $\mathrm{CO}$ concentration field is similar to that of the oxygen concentration field. But the difference is that the area with a relatively high concentration of $\mathrm{CO}$ has a low concentration of oxygen. The CO concentration in the gob gradually increases after the mining starts, extending from the open-off cut to the air return corner of the working face. High concentration of $\mathrm{CO}$ is distributed throughout the gob in-depth with the advance of the working face. It is mainly caused by continuous coal oxidation. According to 


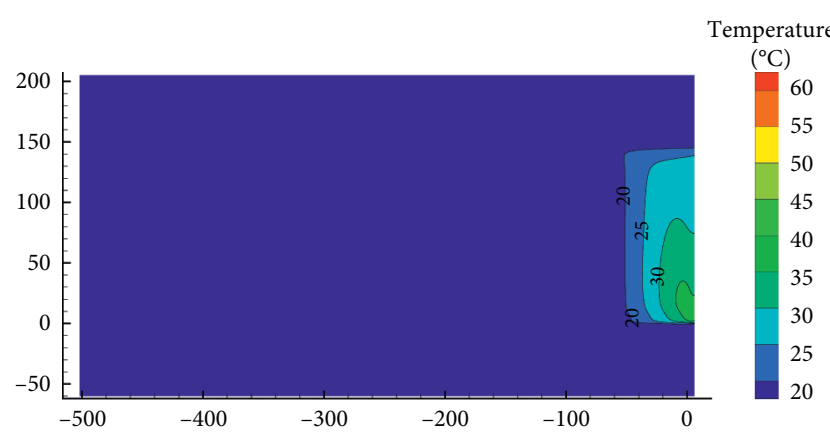

(a)

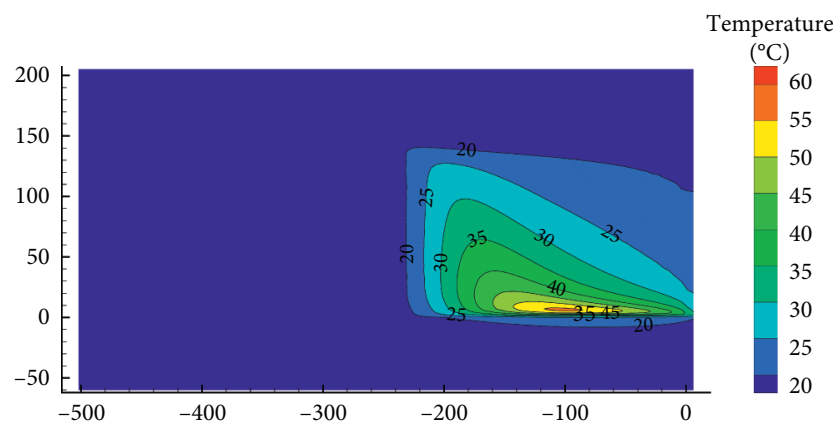

(c)

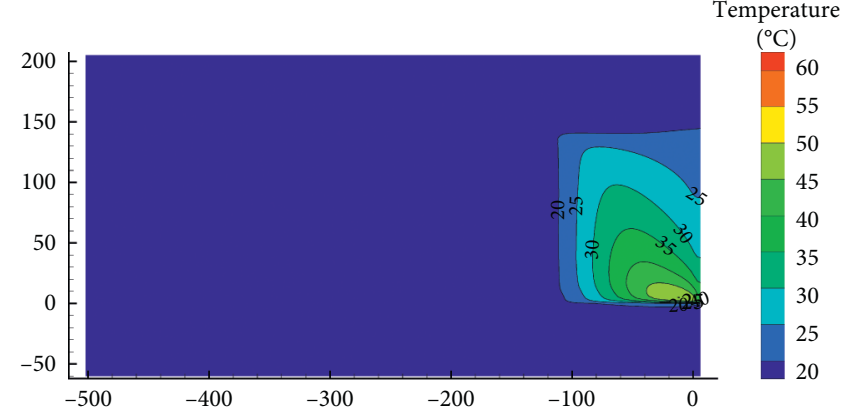

(b)

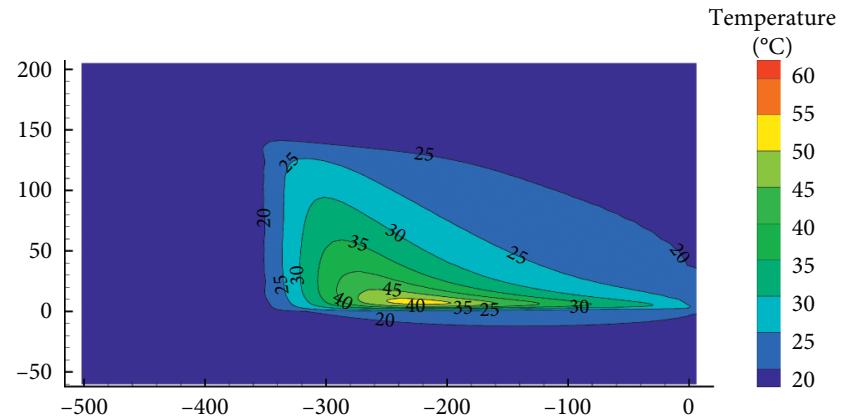

(d)

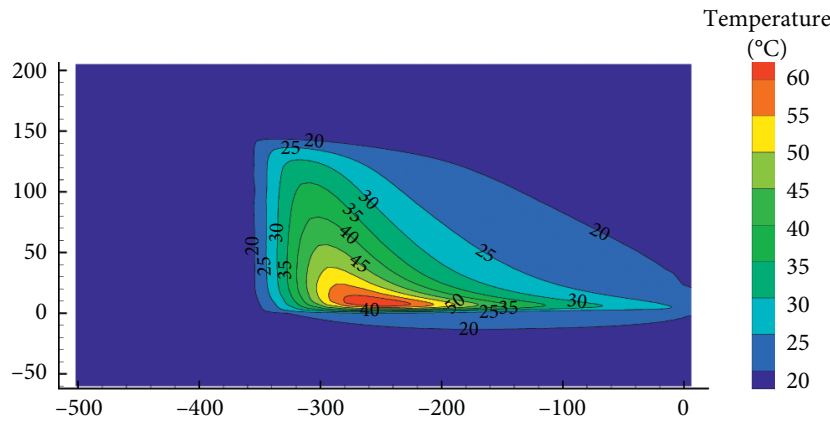

(e)

Figure 6: Dynamic change of temperature field during the advance of the working face. (a) 10 days after the advance of the working face. (b) 20 days after the advance of the working face. (c) 40 days after the advance of the working face. (d) 60 days after the advance of the working face. (e) 10 days after the end of the mining.

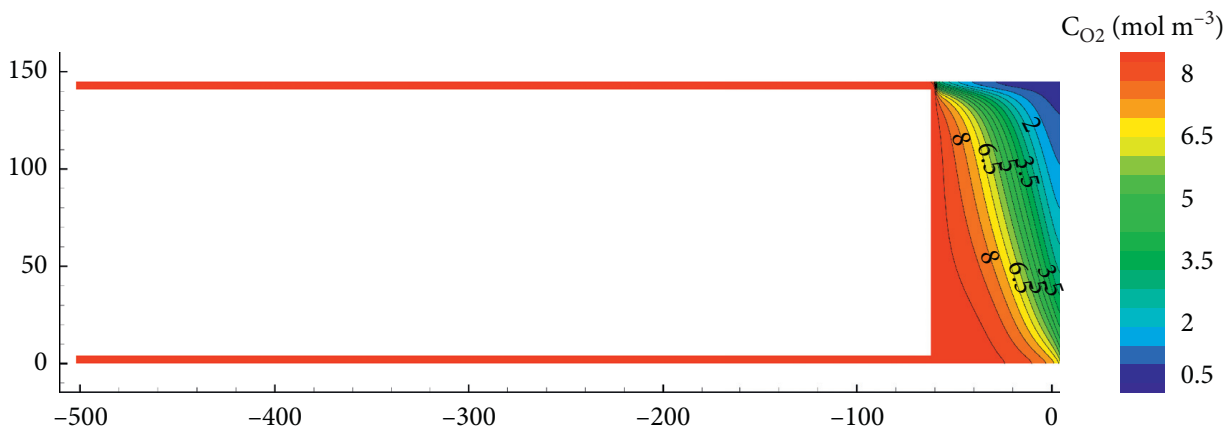

(a)

Figure 7: Continued. 


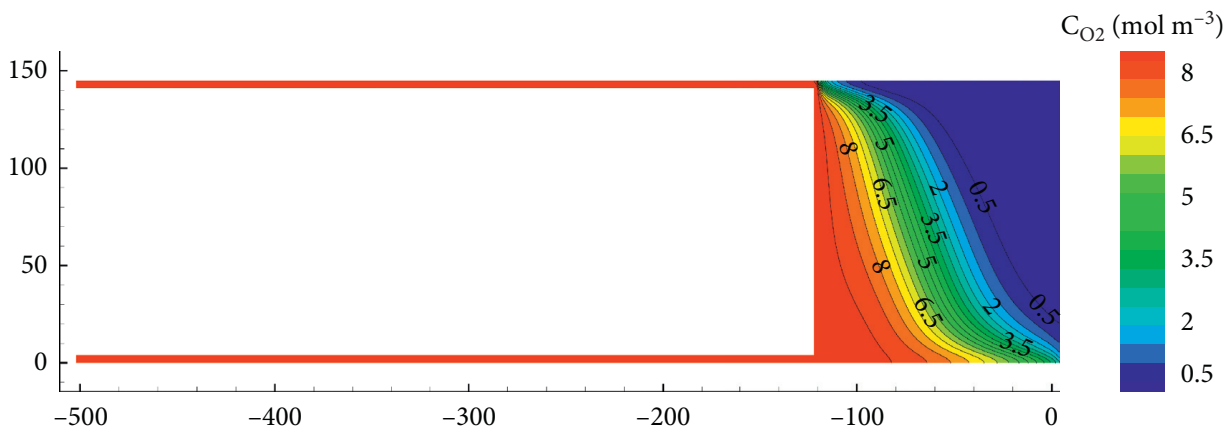

(b)

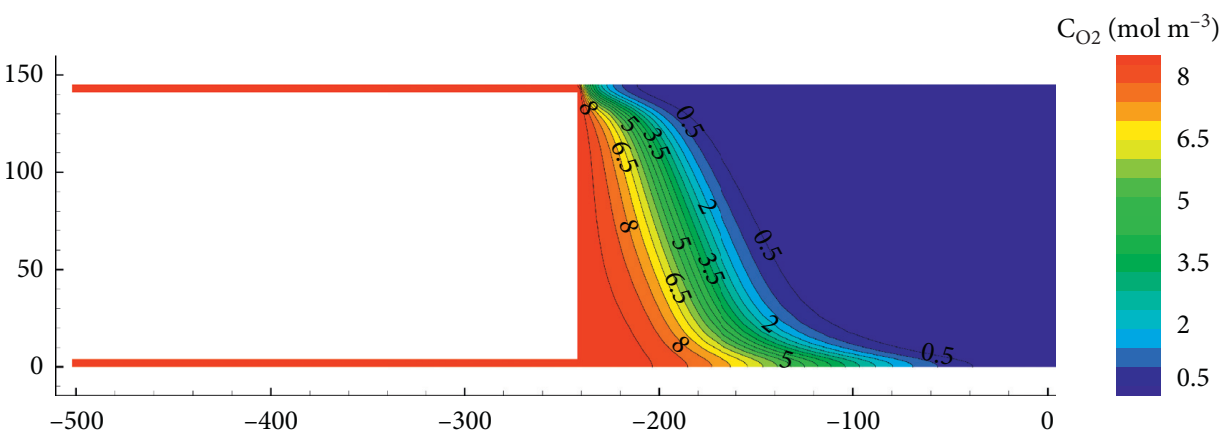

(c)

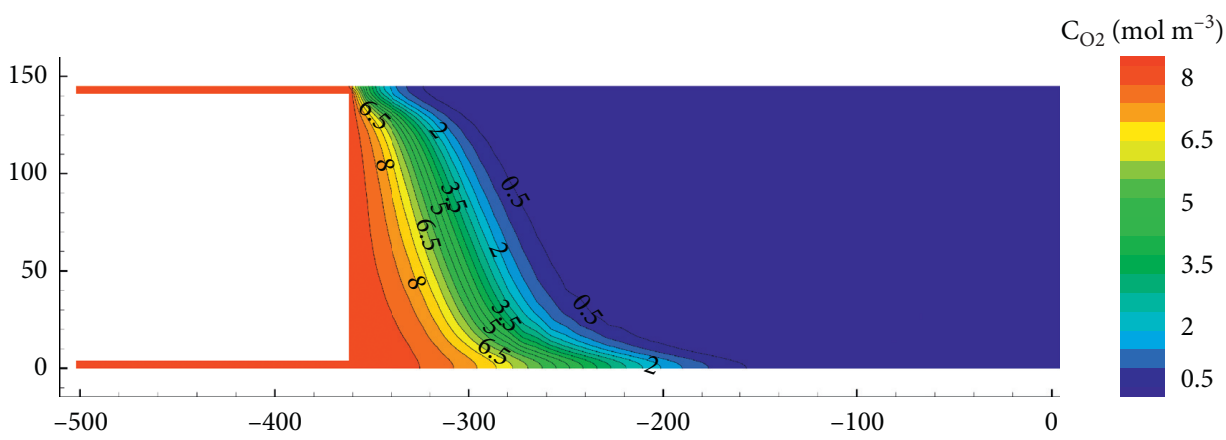

(d)

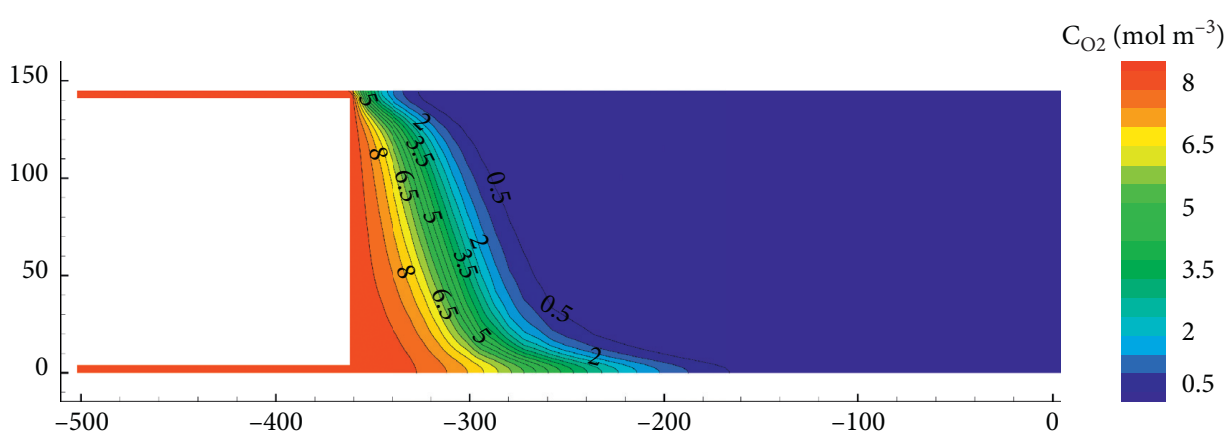

(e)

Figure 7: Dynamic variation of the oxygen concentration field. (a) 10 days after the advance of the working face. (b) 20 days after the advance of the working face. (c) 40 days after the advance of the working face. (d) 60 days after the advance of the working face. (e) 10 days after the end of the mining. 


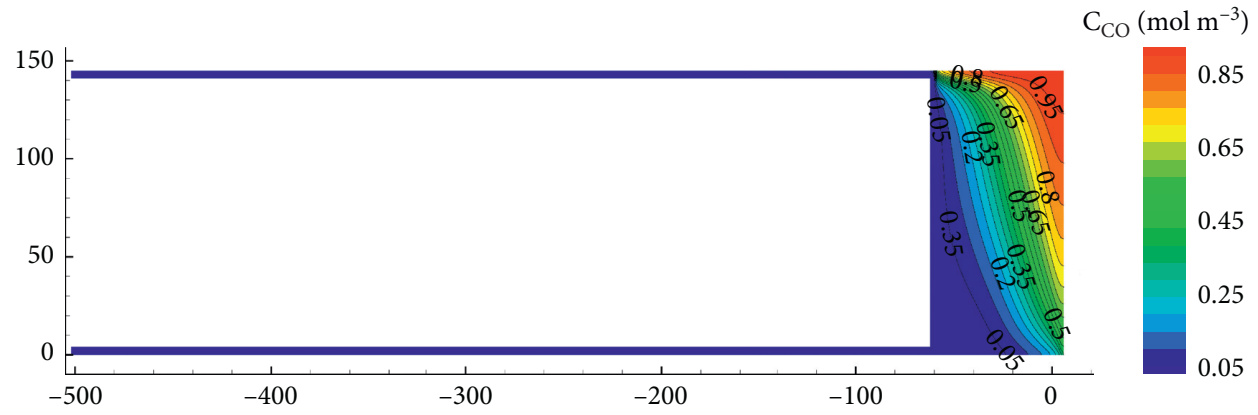

(a)

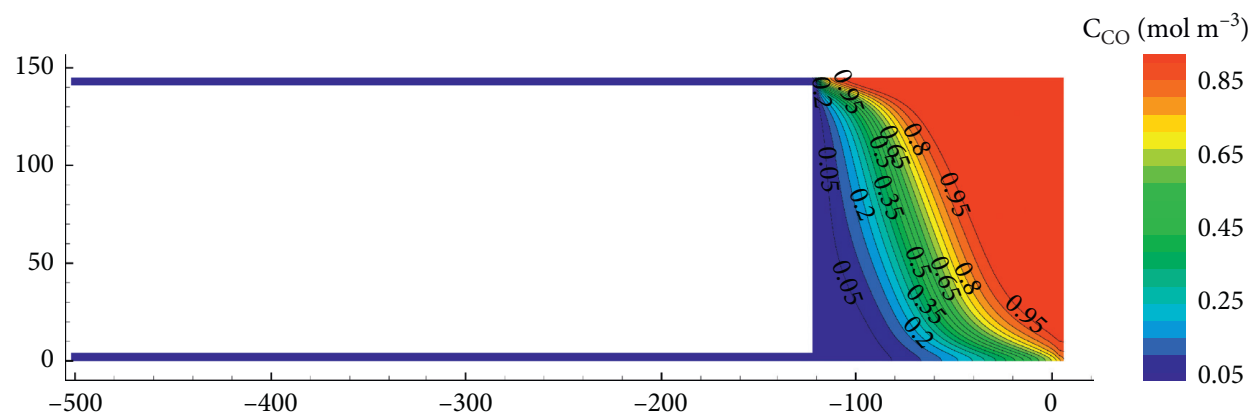

(b)

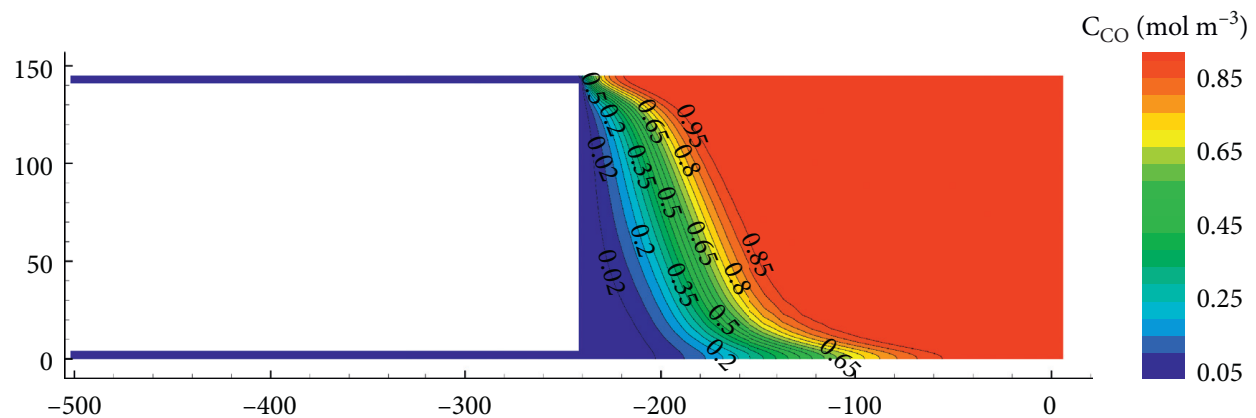

(c)

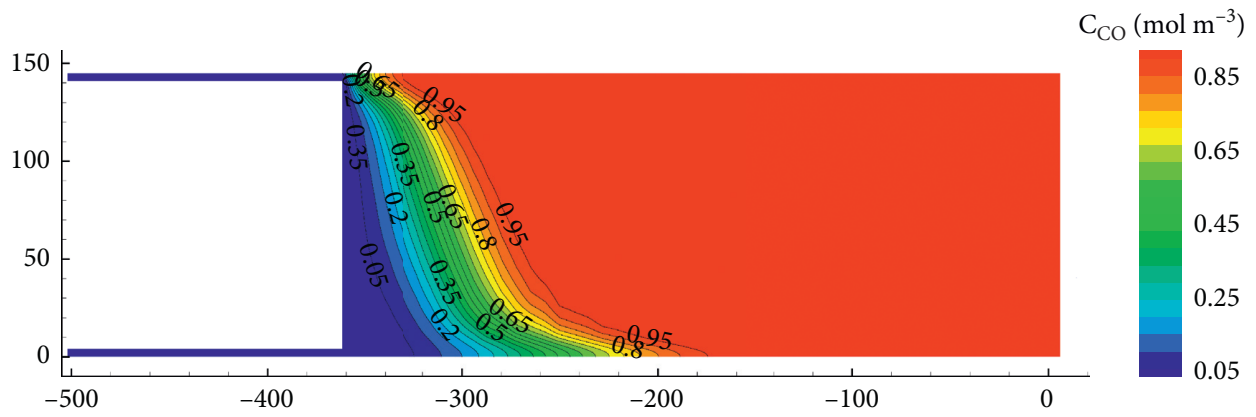

(d)

Figure 8: Continued. 


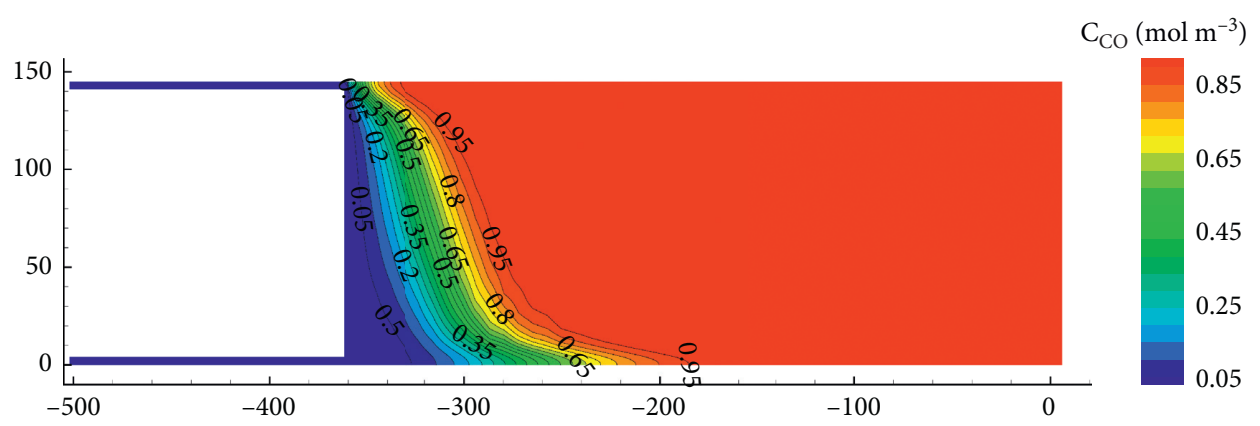

(e)

FIGURE 8: Dynamic variation of the CO concentration field. (a) 10 days after the advance of the working face. (b) 20 days after the advance of the working face. (c) 40 days after the advance of the working face. (d) 60 days after the advance of the working face. (e) 10 days after the end of the mining.

the (16), CO is produced constantly while oxygen is consumed. Due to the weak airflow in the deep gob, CO, which cannot be diluted, accumulates continuously. The temperature of coal-rock next to the working face is relatively low with weak coal-oxygen reaction. As a result, the CO concentration is low under the dilution effect of airflow.

\section{Sensitivity Analysis}

5.1. Effect of Ventilation Temperature. The simulation result of the maximum temperature in the gob under varied ventilation temperatures with the temperature of the surrounding strata of $20^{\circ} \mathrm{C}$ is shown in Figure 9. As can be seen from the figure, the maximum temperature in the gob increases rapidly and then decreases slowly after reaching the maximum temperature over time under varied ventilation temperatures. The reason is that the advance distance of the working face is short at the beginning, and the compaction of the carving rock in the gob is low with small air leakage resistance and large air leakage. Under good oxygen supply conditions, residual coal in an oxygen-rich environment leads to an intense coal-oxygen reaction with a large amount of heat release. Meanwhile, few heats are required for heating the environment of the gob due to a small range of the gob, causing a quick temperature rise in the gob. With the continuous advance of the working face, the strike length of the gob increases with the gob range. However, with more and more low-temperature coal and rock entering the gob, the total amount of oxidation heat of the residual coal no longer increases, and the temperature of the gob decreases slightly. Moreover, although the higher the ventilation temperature, the greater the maximum temperature of the gob, the increase of the maximum temperature is smaller than that of the ventilation temperature. Besides, the maximum temperatures of the gob with different ventilation temperatures are similar at the beginning of the advance of the working face. For example, when the ventilation temperature is $10^{\circ} \mathrm{C}$, the maximum temperature on the 30th day is $55.2^{\circ} \mathrm{C}$; and when the ventilation temperature is $30^{\circ} \mathrm{C}$, the maximum temperature on the 30 th day is $59.4^{\circ} \mathrm{C}$. The ventilation temperature increases by $10^{\circ} \mathrm{C}$, while the increase in the maximum temperature is less than $5^{\circ} \mathrm{C}$. The reason is

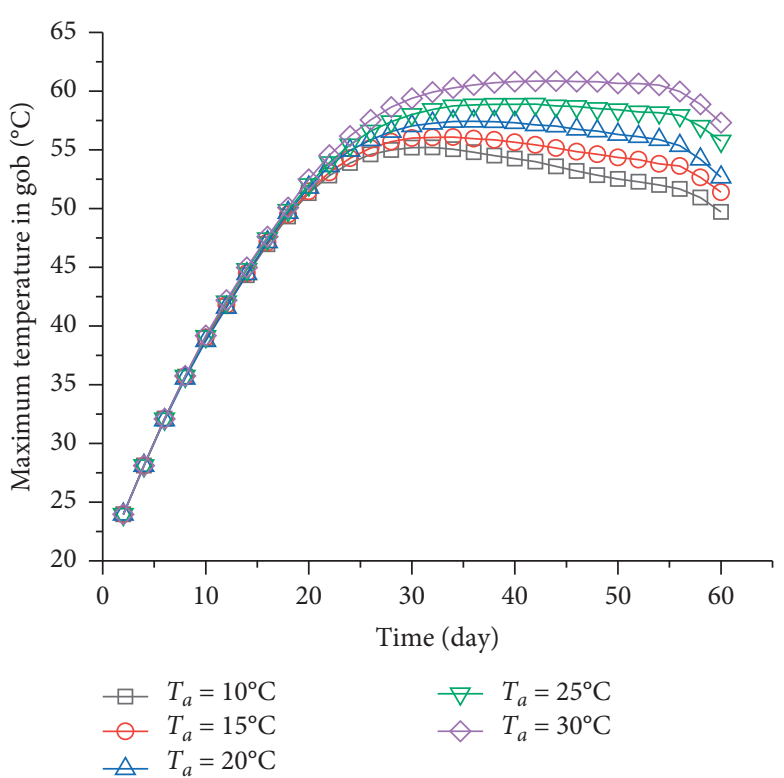

Figure 9: The maximum temperature in the gob under varied ventilation temperatures.

that, before entering the gob, the air conducts heat exchange with the walls of the roadway so that the temperature is reduced.

5.2. Effect of Temperature of the Surrounding Strata. The simulation result of the maximum temperature in the gob under varied temperatures of the surrounding strata is shown in Figure 10. As can be seen from the figure, the maximum ambient temperature in the gob is mainly affected by the temperature of the surrounding strata at the initial mining period, and the temperature in the gob is always higher than that of the surrounding strata temperature. For example, when the surrounding strata temperature is $20^{\circ} \mathrm{C}$, the maximum ambient temperature of the gob is about $24^{\circ} \mathrm{C}$. With the continuous advance of the working face, the maximum ambient temperature of the gob is gradually consistent under different surrounding strata temperatures. 


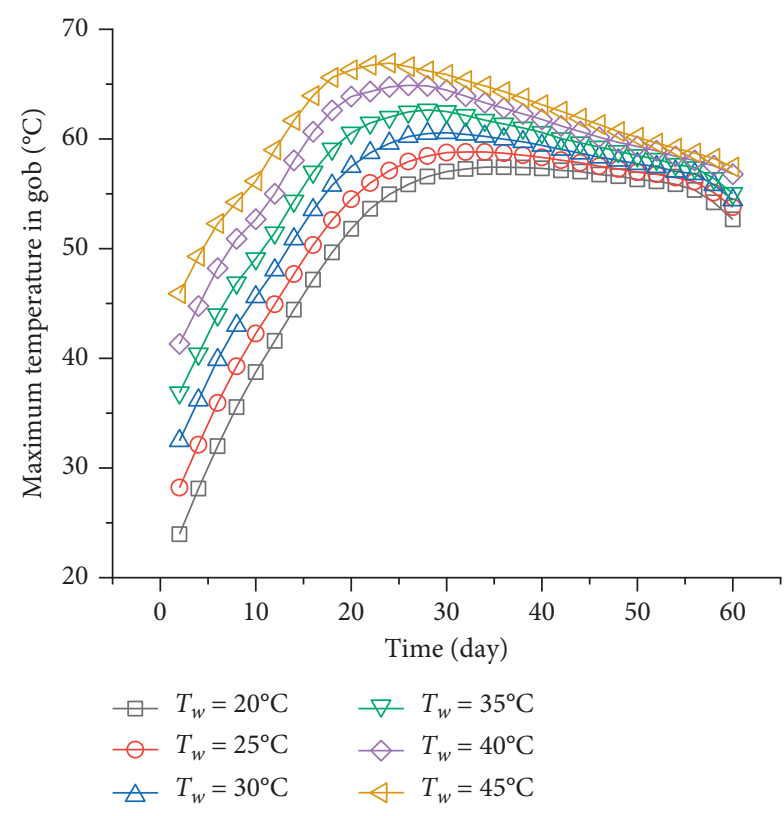

Figure 10: The maximum temperature in the gob under varied temperatures of the surrounding strata.

The reason is that the oxidation of residual coal gradually becomes dominant. In this way, the gob is gradually heated by the heat produced by the oxidation of the residual coal, so that the ambient temperature in the gob gradually tends to be consistent. Furthermore, the tendency of the maximum temperature in the gob increases rapidly and then declines slowly, which is similar to that in Figure 9.

5.3. Effect ofCoal-Rock Particle Size. The simulation result of the maximum temperature in the gob under varied particle sizes of the coal-rock is shown in Figure 11. As can be seen from the figure, the larger the average particle size, the larger the value of maximum temperature in the gob. For example, the maximum temperature with a particle size of $0.04 \mathrm{~m}$ on the 30th day is $56.3^{\circ} \mathrm{C}$, and the maximum temperature with a particle size of $0.12 \mathrm{~m}$ is $104.2^{\circ} \mathrm{C}$. The reason is that the permeability is proportional to the square of the particle size (see (4)). The increase of particle size can improve gob permeability, enhance airflow in the gob, ensure sufficient oxygen supply, enhance the degree of coal-oxygen reaction, and increase the temperature significantly.

5.4. Effect of the Advance Rate. The simulation result of the maximum temperature in the gob under varied advance rates is shown in Figure 12. As can be seen from the figure, the higher the advance rate of the working face, the lower the maximum temperature in the gob. For example, when the advance rate is $2 \mathrm{~m} / \mathrm{d}$, the maximum temperature in the gob is close to $194^{\circ} \mathrm{C}$, and when the advance rate is $8 \mathrm{~m} / \mathrm{d}$, the maximum temperature in the gob is less than $47^{\circ} \mathrm{C}$. The reason is that the faster the working face advances, the faster the residual coal in the gob enters the asphyxiation zone. The coal-oxygen reaction is suppressed with less heat release; thus, the temperature in the gob rises slowly.

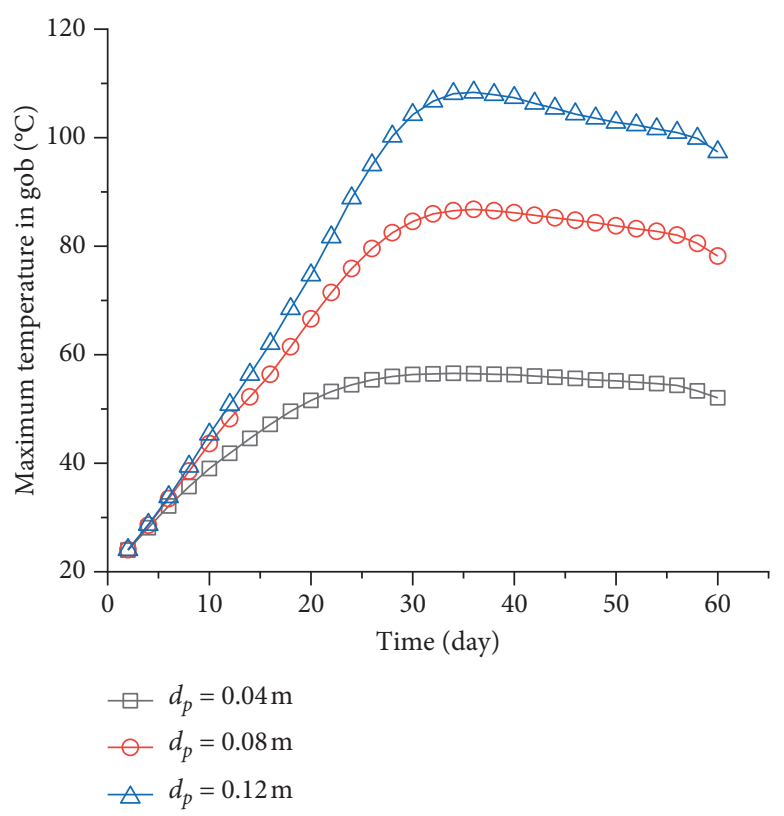

FIgURE 11: The maximum temperature in the gob under varied particle sizes.

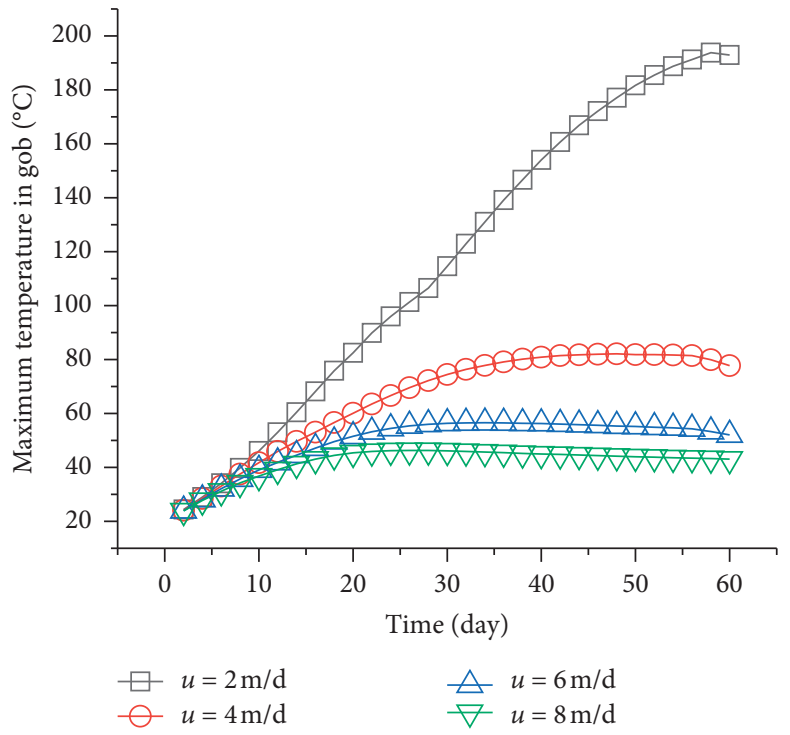

FIgURE 12: The maximum temperature in the gob under varied advance rates.

\section{Conclusion}

A fully coupled transient multiphysical model including gas flow, gas species transport, and heat transfer in the gob and the butt entries, as well as heat transfer in the surrounding strata, is developed to quantify the evolution of coal selfheating in gob during and after mining activities. The rationality of the model was verified by comparing it with the field monitoring data. By analyzing the dynamic variation of the temperature field and oxygen concentration field in the gob during the advance of the working face, some useful conclusions were drawn. 
(1) A tailing phenomenon of the high-temperature area in the temperature field is formed along the air inlet side of the gob. The temperature in the high-temperature area formed during the advance of the working face decreases gradually under the accumulation and compaction of the gob and the heat dissipation of the surrounding strata.

(2) The maximum temperature in the gob increases rapidly and then decreases slowly in the advance process of the working face. When mining stops, the temperature in the gob increases continuously, while the high-temperature zone moves towards the working face.

(3) At the same surrounding strata temperature, different ventilation temperatures nearly have no effect on the maximum temperature of the gob at the initial stage of mining. However, the higher the ventilation temperature, the larger the value of maximum temperature in the gob at the later stage of mining.

(4) The smaller the average particle size of gob material or the higher the advance rate of the working face, the lower the maximum temperature in the gob.

\section{Nomenclature}

$\begin{array}{ll}A: & \text { Preexponential factor }\left(\mathrm{s}^{-1}\right) \\ c: & \text { Solid specific heat }\left(\mathrm{J} \cdot \mathrm{kg}^{-1} \cdot \mathrm{K}^{-1}\right) \\ c_{p}: & \text { Fluid constant pressure specific heat }\left(\mathrm{J} \cdot \mathrm{kg}^{-1} \cdot \mathrm{K}^{-1}\right) \\ C: & \text { Gas concentration }\left(\mathrm{mol} \cdot \mathrm{m}^{-3}\right) \\ d_{p}: & \text { Particles diameter }(\mathrm{m}) \\ d_{x}, d_{y}: & \text { Specific spatial distances }(\mathrm{m}) \\ D: & \text { Diffusion coefficient }\left(\mathrm{m}^{2} \cdot \mathrm{s}^{-1}\right) \\ E: & \text { Activation energy }\left(\mathrm{J} \cdot \mathrm{mol}^{-1}\right) \\ \mathrm{F}: & \text { Radiant flux vector }\left(\mathrm{W} \cdot \mathrm{m}^{-2}\right) \\ H: & \text { Caving height in the gob }(\mathrm{m}) \\ H, & \text { Thickness of the residual coal }(\mathrm{m}) \\ h: & \text { Convective heat transfer coefficient }\left(\mathrm{W} \cdot \mathrm{m}^{-2} \cdot \mathrm{K}^{-1}\right) \\ \Delta H: & \text { Coal oxidation reaction heat }\left(\mathrm{J} \cdot \mathrm{mol}^{-1}\right) \\ K_{p}: & \text { Bulking factor distribution function }(-) \\ k: & \text { Permeability }\left(\mathrm{m}^{2}\right) \\ M: & \text { Mining height of the working face }(\mathrm{m}) \\ n: & \text { Reaction order }(-) \\ p: & \text { Gob gas pressure }(\mathrm{Pa}) \\ q_{s}: & \text { Solid heat generation term }\left(\mathrm{W} \cdot \mathrm{m}^{-3}\right) \\ R: & \text { Gas constant }\left(\mathrm{J} \cdot \mathrm{mol}-1 \cdot \mathrm{K}^{-1}\right) \\ r: & \text { Reaction rate }\left(\mathrm{mol} \cdot \mathrm{m}{ }^{-3} \cdot \mathrm{s}^{-1}\right) \\ T: & \text { Temperature }(\mathrm{K}) \\ \alpha_{x}, \alpha: & \text { Bulking factor attenuation ratios }\left(\mathrm{m}^{-1}\right) \\ \varepsilon: & \text { Porosity in the gob }(-) \\ \rho: & \text { Density }\left(\mathrm{kg} \cdot \mathrm{m}^{-3}\right) \\ \mu: & \text { Dynamic viscosity }(\mathrm{Pa} \cdot \mathrm{s}) \\ \xi: & \text { Adjustment coefficient }(-) \\ \lambda: & \text { Thermal conductivity }\left(\mathrm{W} \cdot \mathrm{m}^{-1} \cdot \mathrm{K}^{-1}\right) \\ \lambda_{R}: & \text { Radiation thermal conductivity }\left(\mathrm{W}^{-1} \cdot \mathrm{m}^{-1} \cdot \mathrm{K}^{-1}\right) \\ s: & \text { Solid phase } \\ f: & \text { Gas phase } \\ b: & \text { Bulk } \\ m: & \text { Mean. } \\ & \end{array}$

\section{Data Availability}

The data used to support the findings of this study are included in the article.

\section{Conflicts of Interest}

The authors declare that they have no conflicts of interest.

\section{Acknowledgments}

The authors gratefully acknowledge the financial support from the National Key R\&D Program of China (Grant no. 2018YFC0807900, Topic 2), the CCTEG Science and Technology Innovation Fund (Grant no. 2018MS015), the Opening Research Fund of State Key Laboratory of Coal Mine Safety Technology (Grant no. SKLCMST104), and the Social Development and Industrialization Guidance Plan of Liao Ning (Grant no. 2019JH8/10300099).

\section{References}

[1] Y. Liang, J. Zhang, L. Wang, H. Luo, and T. Ren, "Forecasting spontaneous combustion of coal in underground coal mines by index gases: a review," Journal of Loss Prevention in the Process Industries, vol. 57, pp. 208-222, 2019.

[2] M. Tutak and J. Brodny, "Determination of particular endogenous fires hazard zones in goaf with caving of longwall," IOP Conference Series: Earth and Environmental Science, vol. 95, no. 4, Article ID 042026, 2017.

[3] M. Tutak and J. Brodny, "The impact of the strength of roof rocks on the extent of the zone with a high risk of spontaneous coal combustion for fully powered longwalls ventilated with the Y-type system-a case study," Applied Sciences, vol. 9, no. 24, p. 5315, 2019.

[4] T. C. Chu, P. Li, and M. G. Yu, "Dynamic simulation of coal spontaneous combustion in gob under working face advancing," Journal of China University of Mining \& Technology, vol. 48, no. 3, pp. 529-537, 2019.

[5] C. S. Zhang, "Research on the space-time evolution law and controlling technology of coal spontaneous combustion in contiguous coal seam's composite long-wall gobs" Ph.D. thesis, Xi'an University of Science and Technology, Xi'an, China, 2019.

[6] M. T. Zhang and J. Y. Wang, "Mathematic model and numerical method for air flow in mine workings," Journal of China Coal Society, vol. 8, no. 3, pp. 46-54, 1983.

[7] M. T. Zhang, J. Y. Wang, and D. Liang, "Numerical modelling of methane migration in air in underground workings," Journal of China Coal Society, vol. 3, pp. 23-30, 1987.

[8] G. X. Ding, Z. Q. Di, and W. X. Ma, "Flow function equation of $2 \mathrm{D}$ nonlinear vadose in mined out area and its fining element method solution," Journal of China Coal Society, vol. 2, pp. 19-25, 1993.

[9] R. L. Zhang, Y. L. Yang, Z. L. Ma et al., "Computer simulation in spontaneous combustion gob's air flowing field, temperature field and heat pressure field," Journal of Jiaozuo Institute of Technology, vol. 17, no. 4, pp. 12-16, 1998.

[10] S. G. Jiang and R. W. Zhang, "Mathematical model and numerical calculation of air flow field in sub-level caving workings," Journal of China Coal Society, vol. 23, no. 3, pp. 36-39, 1998. 
[11] L. M. Du and Y. L. Yang, "Mathematical models of unstable air pressure field and unstable temperature field and heatpressure calculating of three-dimension in the gob," Journal of Jiaozuo Institute of Technology, vol. 18, no. 3, pp. 16-20, 1999.

[12] Z. X. Li, S. Y. Qin, and D. Y. Lu, "Numerical simulation study of fully-mechanized caving coal face in the gob spontaneous combustion," Journal of China Coal Society, vol. 24, no. 5, pp. 494-497, 1999.

[13] Z. X. Li, "Study of coupling of gas and spontaneous combustion in highly gassy and spontaneous combustion gobs," Ph.D. thesis, Liaoning Technical University, Fuxin, China, 2007.

[14] Z. X. Li, D. P. Xu, and L. Q. Liu, "Study on numerical simulation about the dividing of spontaneous ignition "three bands" in operation gob," Journal of Liaoning Technical University, vol. 21, no. 5, pp. 545-548, 2002.

[15] J. C. Xu, "Determination theory of coal spontaneous combustion zone," Ph.D. thesis, China Coal Industry Publishing Home, Beijing, China, 2001.

[16] J. Deng, H. Wen, and J. C. Xu, "Prediction theory and technology of coal spontaneous combustion," Ph.D. thesis, Shanxi Science and Technology Press, Xi'an, China, 2001.

[17] Y. F. Shan, S. G. Wang, and X. H Zhou, "Mathematical model and its solution of simulation calculation for the spontaneous combustion in the stope," Journal of Liaoning Technology University (Natural Science), vol. 21, no. 2, pp. 133-136, 2002.

[18] C. Hua, "Study of the forecast model based on fuzzy seepage theory and resembling simulation about the position of spontaneous combustion in mining field," Ph.D. thesis, Liaoning Technical University, Fuxin, China, 2004.

[19] B. Tan, H. Y. Niu, C. N. He et al., "Gob coal spontaneous combustion temperature field theory and numerical analysis under mining conditions," Journal of Central South University (Science and Technology), vol. 44, no. 1, pp. 381-387, 2013.

[20] T. Xia, F. Zhou, J. Liu, J. Kang, and F. Gao, "A fully coupled hydro-thermo-mechanical model for the spontaneous combustion of underground coal seams," Fuel, vol. 125, pp. 106-115, 2014.

[21] W. Liu, "Multi-ysics Coupling mechanism and threeimensional numerical simulation of spontaneous combustion of gob," Ph.D. thesis, China University of Mining and Technology, Beijing, China, 2014.

[22] J. F. Zhu, W. Cai, and Y. P. Qin, "Mathematical model for spontaneous combustion in gob in the moving coordinates," Journal of China Coal Society, vol. 34, no. 8, pp. 1095-1099, 2009.

[23] B. Taraba and Z. Michalec, "Effect of longwall face advance rate on spontaneous heating process in the gob area-CFD modelling," Fuel, vol. 90, no. 8, pp. 2790-2797, 2011.

[24] J. Brodny and M. Tutak, "The impact of the flow volume flow ventilation to the location of the special hazard spontaneous fire zone in goaf with caving of operating longwalls," in Proceedings of the 16th International Multidisciplinary Scientific GeoConference (SGEM 2016), vol. 2, pp. 897-904, July 2016, Albena, Bulgaria.

[25] H. Wen, "Dynamic numeric simulation of coal self-ignite in gob in fully mechanized caving face," Journal of China Coal Society, vol. 27, no. 1, pp. 54-58, 2002.

[26] Q. L. He and D. M. Wang, "Numerical simulation of spontaneous combustion process in gob areas by fully-mechanized and caving roof coal," Journal of China University of Mining \& Technology, vol. 33, no. 1, pp. 14-17, 2004.

[27] A. Ejlali, D. J. Mee, K. Hooman, and B. B. Beamish, "Numerical modelling of the self-heating process of a wet porous medium," International Journal of Heat and Mass Transfer, vol. 54, no. 25-26, pp. 5200-5206, 2011.

[28] C. Lohrer, M. Schmidt, and U. Krause, "A study on the influence of liquid water and water vapour on the self-ignition of lignite coal-experiments and numerical simulations," Journal of Loss Prevention in the Process Industries, vol. 18, no. 3, pp. 167-177, 2005.

[29] S. Q. Yang, T. Cheng, Q. Xu et al., “Theoretical analysis and numerical simulation of influence of the change of negative pressure and air volume of inner interlocked tail road on coal spontaneous combustion," Journal of China Coal Society, vol. 36, no. 2, pp. 308-312, 2011.

[30] Y. H. Wang, J. L. Wen, Y. P. Qin et al., "Numerical simulation of multi-parameters coupling seepage in gob based on fluidsolid theory," Journal of Liaoning Technical University (Natural Science), vol. 31, no. 5, pp. 760-764, 2012.

[31] Z. X. Li, G. Yi, J. G. Wu et al., "Study on spontaneous combustion distribution of gob based on the "O" type risked falling and non-uniform oxygen," Journal of China Coal Society, vol. 37, no. 3, pp. 484-489, 2012.

[32] L. Yuan and A. C. Smith, "Numerical study on effects of coal properties on spontaneous heating in longwall gob areas," Fuel, vol. 87, no. 15-16, pp. 3409-3419, 2008.

[33] Y. M. Song, "Mechanism of coal spontaneous combustion and partition seepage," Ph.D. thesis, China University of Mining and Technology, Beijing, China, 2012.

[34] J. C. Wang, "Research on temperature field with lowemperature oxidation in gob by numerical simulation," Ph.D. thesis, Anhui University of Science \& Technology, Huainan, China, 2010.

[35] Z. H. Chi, "Research of temperature distribution of coal deposits at the mining scale," Ph.D. thesis, Dalian University of Technology, Dalian, China, 2011.

[36] J. P. Sun, "Numerical simulation of airflow and temperature distribution in mine gobs," Ph.D. thesis, Dalian University of Technology, Dalian, China, 2008.

[37] P. L. Zhou, Y. H. Zhang, Z. A. Huang et al., "4D dynamic simulation of coal oxidation heating law in gobs with heterogeneous porosity," Chinese Journal of Engineering, vol. 38, no. 10 , pp. 1350-1358, 2016.

[38] P. Li, T. X. Chu, and X. Chen, "Simulation on distribution characteristics of coal spontaneous combustion in gob during dynamic advancing of working face," Journal of Safety Science and Technology, vol. 13, no. 10, pp. 122-127, 2017.

[39] T. Xia, X. Wang, F. Zhou, J. Kang, J. Liu, and F. Gao, "Evolution of coal self-heating processes in longwall gob areas," International Journal of Heat and Mass Transfer, vol. 86, pp. 861-868, 2015.

[40] M. G. Qian and T. C. Liu, Mine Pressure and Its Control, China Coal Industry Publishing House, Beijing, China, 1991.

[41] Z. X. Li, Q. Wu, and Z. Q. Wang, "Distribution characteristic of remaining coal oxygen consumption and spontaneous combustion heating-up in gob," Journal of China Coal Society, vol. 34, no. 5, pp. 667-672, 2009.

[42] A. M. Al-Amiri, "Analysis of momentum and energy transfer in a lid-driven cavity filled with a porous medium," International Journal of Heat and Mass Transfer, vol. 43, no. 19, pp. 3513-3527, 2000.

[43] M. Le Bars and M. G. Worster, "Interfacial conditions between a pure fluid and a porous medium: implications for binary alloy solidification," Journal of Fluid Mechanics, vol. 550, no. -1, pp. 149-173, 2006.

[44] D. A. Nield and A. Bejan, Convection in Porous Media, Springer, Cham, Switzerland, 2017. 
[45] S. Wessling, C. Kuenzer, W. Kessels, and M. W. Wuttke, "Numerical modeling for analyzing thermal surface anomalies induced by underground coal fires," International Journal of Coal Geology, vol. 74, no. 3-4, pp. 175-184, 2008.

[46] D. Agonafer, L. G. Li, and D. B. Spalding, "The LVEL turbulence model for conjugate heat transfer at low Reynolds numbers," in Proceedings of the Application of CAE/CAD to Electronic Systems 1996 ASME International Mechanical Engineering Congress and Exposition, pp. 17-22, Atlanta; GA, USA, 1996.

[47] T. Q. Xia, "Multi-ysics coupling mechanism of coxistence hazards for coal spontaneous combustion and gas," Ph.D. thesis, China University of Mining \& Technology, Xuzhou, China, 2015.

[48] Z. D. Yang, "Research on the distribution regularity of three zones in gob based on temperature and density of $\mathrm{O}_{2}$," Journal of North China Institute of Science and Technology, vol. 10, no. 1, pp. 29-32, 2013. 